\title{
A CONSTRUCTIONAL ANALYSIS OF BODILY MOTION EXPRESSIONS
}

\author{
NORIKO NEMOTO \\ Fukushima University
}

\begin{abstract}
This paper examines the kind of motion expressions with verbs relating to contact and those relating to exerting force exemplified by John wiped his hand across his mouth and John pushed his hands into his pockets, where the body-part object must obligatorily be followed by a path phrase. It is pointed out that these apparently similar expressions manifest divergent properties as to the range of body-part objects and passivisation. A close examination of the interaction between verbs and constructions within the framework of Construction Grammar shows that the two groups of verbs acquire the bodily motion usage through different processes. It is also shown that the two differ as to the degree of conflict between the body part and its owner.*
\end{abstract}

Keywords: body-part object, path phrase, internal causation metaphor, Construction Grammar, passive

\section{Introduction}

Motion expressions which encode "X GO Path" in the syntactic frame "NP V XP," as illustrated in (1a), or those which encode "X CAUSE [Y GO Path]" in the syntactic frame "NP V NP XP," as illustrated in (1b), have been extensively studied (e.g. Jackendoff (1990) and Talmy (2003b)).

(1) a. The rock rolled down the hill.

b. I rolled the keg into the storeroom. (Talmy (2003b: 28))

* I would like to express my gratitude to Sean Mahoney and Robert Murphy, who kindly answered my questions about some English data and provided insightful observations. I am also grateful to two anonymous reviewers for their valuable comments and suggestions, which helped me to reduce some of the vagueness and inadequacies found in earlier versions of this paper. This work is financially supported by Grant-in-Aid for Young Scientists (B), No. 18720128, from the Ministry of Education, Culture, Sports, Science and Technology. 
With the latter, much of the discussion has been concerned with cases where an entity $\mathrm{X}$ causes another distinct entity $\mathrm{Y}$ to go somewhere. This paper, however, investigates motion expressions used in the "NP V NP XP" syntactic configuration to describe "X CAUSE [X's body part GO Path]," as exemplified below.

(2) a. Andy says, sitting forward and slapping his hands on his knees ... (BNC)

b. He wiped his hand from brow to chin in the hope of sloughing the illusion off. (BNC)

(3) a. He pushed his hands into his pockets ... (BNC)

b. She threw her arms round the horse's neck ... (BNC)

I will refer to the kind of uses represented by (2) and (3) as the bodily motion use of a verb.

This paper focuses on two groups of verbs that have this bodily motion use. One is verbs relating to contact like slap and wipe. The other is verbs relating to exerting force like push and throw. The two groups of verbs manifest a common syntactic property as to the omissibility of the path phrase, i.e., the path phrase cannot be omitted from the bodily motion use of these verbs. If it were, then the resulting sentence would be taken as the transitive use, where the body-part object is construed as the target of the act encoded by each verb rather than the entity moved in some direction, as shown below.

(4) a. He slapped his hand on the table.

b. \#He slapped his hand. $(\neq(4 a))$

(5) a. John wiped his hand across his mouth.

b. \#John wiped his hand. $(\neq(5 a))$

(6) a. John pushed his hands into his pockets.

b. \#John pushed his hands. $(\neq(6 a))$

(7) a. John threw his arms around her neck.

b. \#John threw his arms. $(\neq(7 \mathrm{a}))$

For example, (4b) can describe an event in which he slapped his left hand with his right hand. Similarly, (6b) can encode an event in which first John pushed his left hand with his right hand and then his right hand with his left one. But these simple transitive sentences cannot encode moving the body part expressed as object in a direction as in the corresponding (a) sentences. ${ }^{1}$ While sentences like (2) (and also

1 I would like to thank Sean Mahoney and Robert Murphy for these observations. 
(4a) and (5a)) have been mentioned in the literature, those like (3) (and also (6a) and (7a)) have escaped the attention of analysts so far. This paper will show that the bodily motion use of verbs like slap and wipe and that of verbs like push and throw manifest different syntactic and semantic properties.

To attain this aim, this study adopts a constructional approach, which seeks to explain the entirety of a language, from the most general to the most idiosyncratic (e.g. Fillmore and Kay (1993), Goldberg (1995), Kay and Fillmore (1999)). In this approach, the cline of grammatical phenomena is to be captured by constructions, which, like traditional idioms, are defined as a pairing of a configuration of syntactic elements with a meaning and/or use. As seen in (4)-(7), the type of act encoded by the bodily motion use is different from that encoded by the simple transitive use. Thus the meaning of the whole sentence, (a), can be said not to be derived from the meanings of its parts, i.e. the transitive sentence, (b), and the path phrase. This leads us to claim that the bodily motion use in (a) must be regarded as involving not the transitive construction plus the path adjunct construction but a separate construction of the form "NP V NP XP."

In a constructional study on argument structure, Goldberg (1995) analyzes sentences like (1a) and (1b) as an instance of constructions called "the intransitive motion construction" and "the caused motion construction," respectively. However, she dose not offer a constructional account of sentences like (2) and (3). This study will propose that to characterize these bodily motion expressions, we need to add a construction which is distinct from the caused motion construction but is linked to it via a metaphor.

The metaphor that the present study adopts is what Lakoff (1996: 112-113) and Lakoff and Johnson (1999:270-271) call "the internal causation metaphor." This metaphor consists of two metaphors: one is the metaphor that causes are forces; the other is the conception of a person as divided into the Subject, which is taken to be the locus of consciousness, judgment, and will, and the Self, which is taken to be other aspects of a whole person such as the body, a past history, and

With (7b), Sean Mahoney has pointed out that it could encode an event in which John has at least three arms and throws more than one severed hand with the hand that is still attached to him, which is unlikely to occur as a real-world event. 
social roles. This metaphor is named the divided-person metaphor. These two metaphors come together in the internal causation metaphor, according to which internal causation is conceptualized as the Subject (a person's consciousness) exerting force on the Self (a part of the body). That is, body control, where a person exerts force on his/her body part to move it, can be understood metaphorically as object control, where a person exerts force on a physical entity or some such entity that can be manipulated like a physical entity. Some of their examples of body control are cited below: ${ }^{2}$

(8) a. I lifted my arm.

b. I can wiggle my ears.

c. I dragged myself out of bed.

Lakoff and Johnson note that (8a) is ambiguous between the object-control sense and the body-control sense. In the object-control sense, I grabbed my left arm with my right arm and moved the left upwards with the right. In the body-control sense, I exerted force on my arm to make it move. Adopting the insights of their studies, this paper makes a distinction between the event of one entity's exerting force on another distinct entity to move it and the event of one entity's exerting force on its part to move it, referring to the former as external causation or object control and the latter as internal causation or body control. ${ }^{3}$

2 The examples of the internal causation metaphor cited in Lakoff (1996) and Lakoff and Johnson (1999) also include the following.

(i) a. I made myself get up early.

b. I restrained myself from hitting him.

c. I held myself back.

What a person controls in these events is not just individual movements of the person's body part but a course of action involving such individual bodily movements. Expressions like these are also analyzed in Talmy (2003a: Ch. 7) in a similar way, though he does not deal with expressions involving body part movements like (8). While we do not bring an analysis of examples like (i) within the scope of this paper, we will review Talmy's analysis of these expressions to have a good grasp of his concept of "force dynamics" in section 4.2.2.

3 In their attempt to characterize the set of verbs participating in the causative alternation, Levin and Rappaport Hovav (1995) introduce a similar pair of notions. They claim that there are verbs that describe an event in which some external cause is implied, "externally caused verbs," and those that describe an event which is brought about because of some property inherent to the argument of the verb, "internally caused verbs." Their aim of introducing these notions is to distinguish 
In section 2, we first review some basic ideas and mechanisms of Goldberg's theory of Construction Grammar. Then I introduce a construction that is needed in characterizing bodily motion expressions. Based on the mechanisms established in section 2, section 3 will demonstrate that verbs like slap and wipe and those like push and throw acquire the bodily motion use in different manners and this difference produces the divergence concerning selection restrictions on the kinds of direct object. Section 4 points out that these two groups of verbs also differ as to passivisation. Adopting Talmy's (2003b: Ch. 7) idea of "force dynamics," this paper will show that the difference in the passivisability comes from the difference concerning force dynamics associated with slap and wipe on the one hand and push and throw on the other. Section 5 aims to explain why the path phrase is obligatory with the bodily motion use of these verbs as shown in (4)-(7). Section 6 makes concluding remarks.

\section{Theoretical Framework}

\subsection{Goldberg (1995)}

Goldberg (1995) presents an analysis of argument structure within the theory of Construction Grammar and argues that argument structures can be regarded as constructions, which are listed in the lexicon as pairings of form and meaning. In her analysis, semantic roles associated with verbs, i.e. participant roles, are distinguished from those associated with constructions, i.e. argument roles. Participant roles are characterized with reference to rich frame-semantic knowledge. ${ }^{4}$ The framesemantic nature of participant roles contrasts with the schematic nature of argument roles such as an agent, a patient, and a goal. In this approach, a given verb can occur in a given construction when the event type encoded by the verb is related to the one encoded by the construction in certain ways. When participant roles and argument roles are semantically compatible they can fuse with each other.

between the verbs associated with the two notions, which contrasts with our aim. In the present analysis, the pair of notions is employed to understand one in terms of the other. I will not go into detail about how their distinction differs from ours.

${ }^{4}$ See Fillmore (1982) for details of the notion of a frame. See also Fillmore and Atkins $(1992,1994)$ for a frame semantic analysis of a lexical item. 
Among some argument structure constructions discussed in Goldberg (1995), those which are relevant to our discussion include the transitive, intransitive motion, and caused motion constructions. This paper will represent these constructions using not Goldberg's (1995) notation but a simpler and more theory-neutral one as in Goldberg and Jackendoff (2004) for the sake of exposition.

(9) Transitive construction

syntax: NP V NP

semantics: X ACTS ON Y

(10) Caused motion construction

syntax: NP V NP XP

semantics: X CAUSE [Y GO Path]

(11) Intransitive motion construction

syntax: NP V XP

semantics: Y GO Path

As discussed in Kay and Fillmore (1999), one of the advantages of Construction Grammar is that this approach can characterize not only relatively idiomatic constructions but also the interaction of such constructions with the more familiar constructions. The idea of inheritance allows us to determine how much of a given construction can be attributed to information associated with it and how much can be explainable in terms of other constructions. This point is also discussed in Goldberg (1995), who shows that while constructions are stored pairings of form and meaning, they do not constitute an unstructured set; rather they form a network and are related to each other by some inheritance links. Goldberg (1995: 75-81) provides four types of inheritance links: instance links, subpart links, metaphorical extension links, and polysemy links, which can be summarized as below.

(12) Instance links $\left(\mathrm{I}_{\mathrm{I}}\right)$ : These are posited when a given construction is a more fully specified version of another construction.

(13) Subpart links $\left(I_{S}\right)$ : These are posited when one construction is a proper subpart of another construction that exists independently.

(14) Metaphorical extension links $\left(\mathrm{I}_{\mathrm{M}}\right)$ : These are posited when two constructions are related by a metaphoric mapping.

(15) Polysemy links $\left(\mathrm{I}_{\mathrm{P}}\right)$ : These are posited when a construction is associated with a family of related senses to capture the semantic relations between the central sense and any extensions from the sense. 
With these inheritance links, Goldberg (1995: 109) represents the relations among the argument structure constructions discussed in her study. In her diagram of the inheritance network, the relationships between the three constructions in (9)-(11) are represented as follows:

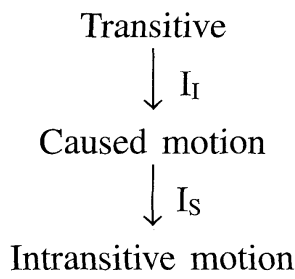

Figure 1

Goldberg (1995: 98-99) notes that a particular constituent of a construction may also inherit some information from other constructions. She observes that the verb drive encodes a special sense only when it occurs in the resultative construction, as illustrated below (p. 79).

(16) Chris drove Pat mad/bonkers/bananas/crazy/over the edge.

She explains that the special sense of drive in the resultative construction is related to the basic sense of the verb via the metaphor "Change of State as Change of Location."

\subsection{Internally versus Externally Caused Motion}

So far we have cited from Goldberg's constructional analysis of argument structure some analytical tools for motion events. While the study offers the constructions needed for characterizing a case where an entity moves in a particular direction (i.e. the intransitive motion construction) or an entity causes something else to move in a particular direction (i.e. the caused motion construction), it does not offer any construction needed for depicting a motion event where an entity causes its own part to move in a particular direction, with the part expressed as direct object. Using the notions presented in the introduction, the event encoded by the bodily motion use can be seen as a case of internal causation, i.e., an entity exerts force on its own part to move it, which is distinguished from external causation, i.e., an entity exerts force on another distinct entity to move it. As shown by the ambiguity of Lakoff and Johnson's example in (8a), this distinction is needed for characterizing the nature of motion events appropriately.

My claim is that what Goldberg and others call "the caused motion 
construction" is employed in describing motion involving external causation, and we need to posit a construction for describing motion involving internal causation. Referring to the former as "the externally caused motion construction" and the latter as "the internally caused motion construction," this paper will define these two constructions as follows: (Pro indicates a pronoun that is coreferential with the NP subscribed ${ }_{i}$.)

(17) Externally caused motion construction syntax: NP V NP XP semantics: X CAUSE [Y GO Path]

(18) Internally caused motion construction

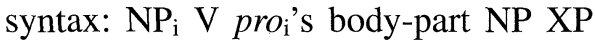
semantics: X CAUSE [X's body part GO Path]

Note that since body control as opposed to object control can only be exercised by the owner of the body part, the possessive pronoun in the internally caused motion construction, by its very nature, must be coreferential with the subject NP.

As we have reviewed in the preceding section, in Construction Grammar, constructions are seen as related to each other by inheritance links to form a network. Let us consider how the internally and externally caused motion constructions are related to each other in the network. As discussed in Lakoff (1996) and Lakoff and Johnson (1999), internal causation is metaphorical external causation. Thus internally caused motion is understood metaphorically as externally caused motion. Then, the internally caused motion construction can be said to be related to the externally caused motion construction via a metaphorical extension link, forming the following network.

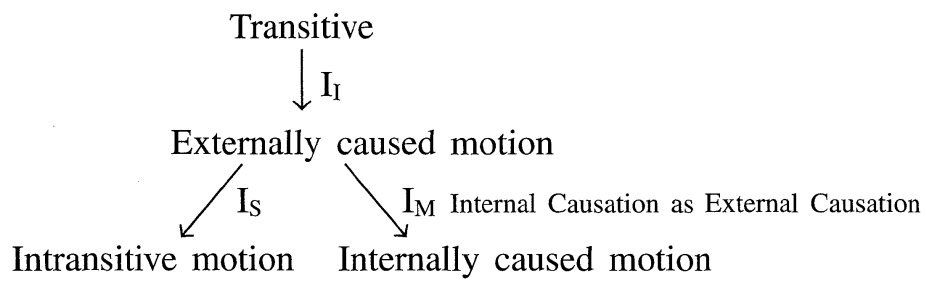

Figure 2

An argument for the existence of the internally caused motion construction has already been suggested in the introduction. Refer back to the meaning contrast between the pairs of sentences in (4)-(7). It 
shows that with these verbs the event of moving the body part expressed as object in a direction can only be encoded when the path phrase is present. Since bodily motion expressions like the (a) sentences cannot be licensed by the transitive and path adjunct constructions in combination, we need to posit an independent construction that licenses those sentences.

Finally let us introduce the argument roles of some constructions which are relevant to the following discussion. The argument roles of the transitive construction are called the agent and the patient. $^{5} \mathrm{We}$ will identify the argument roles of the externally caused motion construction as the cause, the external-theme, and the path, and those of the internally caused motion construction as the cause, the internaltheme, and the path.

\section{The Interaction between Verbs and Constructions}

Having introduced some of the machinery of the Construction Grammar framework, we now proceed to our bodily motion examples given in the introduction. As we have stated there, we concentrate our attention on two groups of verbs which can be used to denote the event of moving the body part represented as object in a direction only when they are used with a path phrase: verbs relating to contact like slap and wipe on the one hand and verbs relating to exerting force like push and throw on the other.

\subsection{The Case of Verbs Relating to Contact}

Let us first examine bodily motion expressions with verbs relating to contact like slap and wipe. The use in question is often addressed in the context of the so-called with/against alternation, exemplified by (19). (See Dowty (1991), Fillmore (1977), Grunau (1985), among others for

5 Goldberg (1995: 116-117) identifies the argument roles of the transitive construction as "proto-agent" and "proto-patient," adopting Dowty's (1991) idea, according to which proto-agent has properties such as "volitional involvement in the event or state," "sentience (and/or perception)," and "causing an event or change of state in another participant," and proto-patient has properties such as "undergoes change of state," "incremental theme," and "causally affected by another participant." (See Dowty (1991) for more discussion.) While I agree with this view, I use the terms agent and patient for the sake of simplicity. 
discussion.)

(19) a. I hit the stick against the fence. (Fillmore (1977: 75))

b. I hit the fence with the stick.

(ibid.)

According to Fillmore, hit has two perspectival options for conceptualizing an event of contact by impact: in one choice, the actor and the manipulated object are brought into perspective, as in (19a); in the other choice, the actor and the affected object are brought into perspective, as in (19b). Fillmore also observes that in (19a), the prepositional phrase is obligatory. Thus (19a) cannot be abbreviated to (20a), which contrasts with a semantic affinity between (19b) and (20b).

(20) a. I hit the stick.

b. I hit the fence.

As a verb of contact by impact, slap behaves like hit (e.g. Dowty (1991), Levin (1993), and Ruhl (1989)). Thus we can characterize the participant roles of a slapping event and the relation between these roles as follows:

(21) Roles: slapper, intermediate, slapped

Relation: A slapper aims an intermediate at a slapped and the intermediate makes contact with the slapped.

As with a hitting event, a slapping event allows two perspectives: in one perspective, the relation between the slapper and the slapped is highlighted; in the other perspective, the relation among the three participants, i.e., a slapper causes a body-part intermediate to go to a slapped, is highlighted. Thus slap can appear in either the transitive construction or the internally caused motion construction. The correspondence between argument roles and participant roles can be expressed as follows:

(22) Transitive + slap

e.g. He laughed and slapped the table[.] (BNC)

participant roles: <slapper, slapped>

argument roles: [agent, patient]

(23) Internally caused motion + slap

e.g. He slapped his hand on the table.

participant roles: <slapper, intermediate, slapped>

argument roles: [cause, internal-theme, path]

Similarly with verbs of contact through motion like wipe. We can identify the participant roles of a wiping event and the relation between these roles as follows: 
(24) Roles: wiper, intermediate, wiped

Relation: A wiper moves an intermediate across the surface of the wiped.

The wiping event also allows two perspectives: one of them focuses on the relation between the wiper and the wiped, which is construed as that between an agent and a patient; the other focuses on the relation among the three participants. When the intermediate is a physical object like a towel, the externally caused motion interpretation is obtained; and when the intermediate is a body part like a hand, the internally caused motion interpretation is obtained. Thus wipe can occur in the transitive construction, as in (25), the externally causedmotion construction, as in (26), or the internally caused motion construction, as in (27). ${ }^{6}$

(25) Transitive + wipe

e.g. He wiped his mouth and walked quietly from the cabin.

(BNC)

participant roles: <wiper, wiped>

argument roles: [agent, patient]

(26) Externally caused motion + wipe

e.g. He wiped the cloth across his face.

participant roles: <wiper, intermediate, wiped>

argument roles: [cause, external-theme, path]

(27) Internally caused motion + wipe

${ }^{6}$ Apart from the internal-theme and external-theme interpretations in (26) and (27), the intermediate role of wipe allows the instrument and location interpretations, when the wiped role is construed as an instance of the patient in the transitive construction. The manner of fusion of roles on each interpretation can be represented as follows.

(i) [Transitive + instrument-adjunct] + wipe e.g. He wiped his mouth with the back of his hand. (BNC) participant roles: <wiper, wiped, intermediate> argument roles: [agent, patient] + [instrument]

(ii) [Transitive + location-adjunct $]+$ wipe e.g. He wiped his hand on the towel. participant roles: <wiper, wiped, intermediate> argument roles: [agent, patient] + [location]

See Nakau (1997a) for discussion of an instrument-location dual. 
e.g. John wiped his hand across his mouth.

participant roles: <wiper, intermediate, wiped>

argument roles: [cause, internal-theme, path]

As evidence for the distinction between the internally and externally caused motion constructions, I point out that wipe sentences with the two constructions differ as to passivisability. Externally caused motion wipe, as in He wiped the cloth across his face, can be used in the passive. Thus the external-theme can be passive subject, as in The cloth was wiped across his face. By contrast, internally caused motion wipe, as in John wiped his hand across his mouth, cannot be passivised. Thus, the internal-theme cannot be passive subject, as shown by the unacceptability of *His hand was wiped across his mouth (see section 4 for discussion of passives).

In this section, we have characterized the bodily motion use of verbs relating to contact like slap and wipe by considering it in relation to other uses of these verbs. To recapitulate, the relation between this use and the transitive use is such that both uses are linked to a common background frame and the two uses highlight different aspects of the common frame. The bodily motion use highlights the relation between an actor (e.g. a slapper), an intermediate and a target (e.g. a slapped); and the transitive use highlights that between an actor and a target. Borrowing a term used in Norvig and Lakoff (1987), the bodily motion use is linked to the transitive use via "profile shift."

\subsection{The Case of Verbs Relating to Exerting Force}

Next, let us examine the bodily motion use of verbs relating to exerting force like push and throw. The relation between the transitive and bodily motion uses of these verbs differs from the case of verbs relating to contact like slap and wipe. This paper assumes that the transitive and bodily motion uses of push or throw involve different senses of these verbs. As addressed at the end of section 2.1, this sort of assumption is made in Goldberg (1995: 98-99) when she explains the meaning of resultative expressions with drive like (16). She takes the special sense of drive in the resultative construction to be related to its basic sense by the common metaphor that change of state is change of location. This paper refers to push encoding an object-control scene as object-control push and push encoding a body-control scene as bodycontrol push. Similarly with throw. This paper claims that object-con- 
trol push or throw is integrated into the transitive construction and body-control push or throw is integrated into the internally caused motion construction.

We will identify the participant roles of object-control push and the relation between these roles as follows:

(28) Roles: a pusher, external-pushed

Relation: A pusher exerts force on an external-pushed to move it.

The participant roles of body-control push and the relation between these roles are defined below:

(29) Roles: a pusher, internal-pushed

Relation: A pusher exerts force on an internal-pushed to move it.

The relation between object-control push and body-control push is captured by the internal causation metaphor, a metaphor that is employed in capturing the relation between the internally and externally caused motion constructions. As part of source domain knowledge, we know that when a person pushes or throws a physical entity s/he manipulates the entity with force or with a sudden movement. This information is mapped onto the target domain. Thus body-control push involves the notion of force or suddenness and encodes some act needing force or a sudden movement (see also the discussion in section 4.2.3). ${ }^{7} \mathrm{We}$ assume that the same line of analysis applies to the case of throw, though pushing and throwing can be distinguished at a level of finer detail, i.e., in a throwing act, but not a pushing act, the actor lets go of the entity s/he holds. However, at the level which is relevant to our discussion we need not refer to such a difference. We will return to this point in section 5 .

With these roles, we can represent the manner of fusion found in the transitive use of push and throw as follows.

7 In this connection, Kageyama and Yumoto (1997: 161) note that verbs like push and pull have an intransitive use encoding motion, as in (i).

(i) a. He heard Carol's car pull into the drive.

b. It's time I was pushing along now.

c. Just shove off and leave me alone!

They observe that these examples do not describe a normal pulling or pushing event but they describe forceful or rapid motion of an entity, which is taken to be characteristic of a normal pushing or pulling event. 
(30) Transitive + object-control push

e.g. Sound of the train getting closer and before I knew it I was out on that street pushing the trolley. (BNC)

participant roles: <pusher, external-pushed>

argument roles: [agent, patient]

(31) Transitive + object-control throw

e.g. When she had thrown the gravel, there had been someone in the pill-box directly ahead of her. (BNC)

participant roles: <thrower, external-thrown>

argument roles: [agent, patient]

The bodily motion use is obtained when body-control push or throw is integrated into the internally caused motion construction, as shown below.

(32) Internally caused motion + body-control push e.g. John pushed his hands into his pockets. participant roles: <pusher, internal-pushed> argument roles: [cause, internal-theme, path]

(33) Internally caused motion + body-control throw e.g. John threw his arms around her neck. participant roles: <thrower, internal-thrown> argument roles: [cause, internal-theme, path] In the event of throwing a physical entity, the entity goes somewhere; and in the event of pushing a physical entity or some such entity, the entity pushed may undergo a displacement. Thus object-control push and throw can also occur in the externally caused motion construction, as shown below:

(34) Externally caused motion + object-control push $[\mathrm{H}] \mathrm{e}$ pushed the cassette into the tape deck ... (BNC) participant roles: <pusher, external-pushed> argument roles: [cause, external-theme, path]

(35) Externally caused motion + object-control throw e.g. I kept throwing the ball back to the wrong player.

(BNC)

participant roles: <thrower, external-thrown> argument roles: [cause, external-theme, path] 
This section has offered a description of the bodily motion use of verbs relating to exerting force like push and throw by considering how it is related to other uses of these verbs. To sum up, the transitive and bodily motion uses involve different senses of these verbs: the transitive use is obtained through the integration of object-control push or throw into the transitive construction; and the bodily motion use is obtained through the integration of body-control push or throw, which is a metaphorical extension from object-control push or throw, into the internally caused motion construction.

\subsection{Selection Restriction on the Kinds of Body-Part Objects}

From these considerations, we can identify the verb and construction involved in the bodily motion expressions in (4)-(7) as follows.

(4) a. He slapped his hand on the table. (Internally caused motion + slap)

(5) a. John wiped his hand across his mouth. (Internally caused motion + wipe)

(6) a. John pushed his hands into his pockets. (Internally caused motion + body-control push)

(7) a. John threw his arms around her neck. (Internally caused motion + body-control throw)

This analysis suggests that in the case of slap or wipe, the bodily motion use can encode the same slapping or wiping act as that expressed in a simple transitive sentence with these verbs. This sharply contrasts with the case of push or throw, where the bodily motion use cannot encode the same type of pushing or throwing act as the transitive use of these verbs. That is, the bodily motion use refers to an event in which a person exerts force on the part of his own body to move it in a particular direction; and the transitive use refers to an event in which a person exerts force on another entity that is distinct from the body part moved to perform the act. ${ }^{8}$

This difference lies in the divergence between the two groups of

8 While I propose to draw a distinction between a body control scene and an object control scene in the characterization of the semantics of verbs like push and throw, this proposal does not entail that the distinction between the two types of scenes figures in characterizing the meanings of any verb that can take either a physical object or a body part as its object. 
verbs as to selection restrictions on the kinds of body-part objects. With slap and wipe, the body parts expressed as the direct objects are restricted to those that are used in common slapping and wiping acts. In a slapping or wiping act, a hand serves as an intermediate and thus these verbs take a hand or some such body part as their objects, as shown below.

(2) a. Andy says, sitting forward and slapping his hands on his knees ...

(36) The captain slapped her palm on the desk with a sound like a breaking plate. (BNC)

(2) b. He wiped his hand from brow to chin in the hope of sloughing the illusion off.

In contrast, the body parts that the bodily motion use of push or throw can take are not limited to the body parts that usually function as an intermediate when one pushes or throws an external physical object. Thus the verb push is compatible with not only an arm or a hand but also with a foot, a head, or a face, as exemplified below.

(37) a. Sliding off the bed, Tug pushed his feet into his trainers and laced them up. (BNC)

b. Tug pushed his head deeper into the soft, musty cushions. (BNC)

Similarly, the verb throw can take as its object a leg or a head as well as an arm or a hand, as shown below.

(38) a. She dragged the bicycle from the shed ... and somehow managed to throw her leg, encumbered by her heavy skirts, over the high framework ... (BNC)

b. [S]he saw a man throw his head back and shake it as if intoxicated, while holding his arms extended ... (BNC)

This difference between the two groups of verbs cannot be explained if we just characterize the bodily motion use of these verbs uniformly as encoding an event in which a person moves his/her body part in a way characteristic of the event described by the verb. The present analysis shows that this difference concerning selection restrictions can be attributed to the difference in the process through which each group of verbs obtain the bodily motion use.

\subsection{Other Verbs}

Here, I will briefly introduce some other verbs allowing the bodily motion use from the classes of verbs that are semantically related to the 
verbs examined above, i.e. slap, wipe, push, and throw, with the aim of showing that allowing the bodily motion use cannot simply reflect idiosyncratic properties of these individual verbs. With verbs encoding contact by impact like slap, verbs that allow the bodily motion use include bang, beat, smack, and tap, as exemplified below.

(39) a. Graham banged his fist angrily on the table.

b. She beat her fists on his back, kicked and shouted and threatened, all to no avail.

c. She smacked her hand down onto the saucer without realising she still held the cup.

d. Markby tapped his fingers on the table top and hissed with exasperation. (all from BNC)

With verbs that encode contact through motion like wipe, the verbs lick, rub, and smooth have the bodily motion use, as illustrated below.

(40) a. Donna licked her tongue across her dry lips ...

b. Luke rubbed his hand across his eyes and nose.

c. With a little smile, she smoothed her hand across the creased piece of paper.

(all from BNC)

As for verbs encoding the exertion of a force on an entity like push, verbs allowing the usage in question include jerk, pull, shove, and thrust, as shown below.

(41) a. He jerked his head towards the door.

b. $[\mathrm{H}] \mathrm{e}$ was in fact pulling his head back with even more tension than before.

c. $[\mathrm{H}] \mathrm{e}$ shoved his hands into his trouser pockets.

d. He thrust his hands into his pockets and moved to the window ...

(all from BNC)

Finally, as for verbs encoding causation of motion by imparting a force like throw, the verbs fling, shoot, slam, and toss, among others, allow this usage, as illustrated below.

(42) a. She flung her arms around him.

b. Then he shot his legs up into the sky and slid down without a splash.

c. She slammed her hands on the desk and papers flew in every direction.

d. The TV reporter chuckled and tossed her head back.

(all from BNC)

While I expect that the semantically related verbs cited above show the same properties as to the omissibility of the path phrase, selection 
restrictions on the kinds of object NPs, and passivisability, an examination of each verb's behavior goes beyond the scope of this paper and I will continue to concentrate on the behavior of slap and wipe on the one hand and push and throw on the other.

\section{Passives}

\subsection{Basic Facts}

As another difference between bodily motion expressions with these two groups of verbs, let us examine passivisation. The verbs slap and wipe do not allow their body-part objects to be expressed as subjects of corresponding passive sentences, as shown below. ${ }^{9}$

(43) a. He slapped his hand on the table.

b. *His hand was slapped on the table.

(44) a. He wiped his hand across his mouth.

b. *His hand was wiped across his mouth.

By contrast, the verbs push and throw are open to passivisation, as illustrated below.

a. He pushed his hands into his pockets.

b. His hands were pushed into his pockets.

(46) a. He threw his arms around her neck.

b. His arms were thrown around her neck.

Let us elaborate on the semantics of passive sentences with push and throw. As is well known, a passive sentence can involve the stateprocess ambiguity (e.g. Curme (1931: 443-447), Jespersen (1927: 389), Nakau (1997b)). Langacker (1982: 61) illustrates this point by citing (47), which is ambiguous between the reading indicated by (48a) and that indicated by (48b).

(47) The town was destroyed.

9 While these passive sentences are unacceptable on the intended interpretation, i.e. the body-control interpretation, the object-control interpretation, where a body part is separated from a person who moves it, is possible, though unlikely. Thus, (43b) evokes an event in which the body part in question has been separated from the original owner and the severed hand was thrown hard onto the table. Similarly, (44b) evokes an event in which another person took his arm and wiped his mouth with it. I would like to thank Sean Mahoney and Robert Murphy for these observations. 
(48) a. The town was already destroyed when we got there.

b. The town was destroyed house by house.

Langacker observes that (48a) denotes only the final state in the process of destruction; but (48b) denotes all the states within the process.

Taking this distinction into consideration, we can observe that push and throw allow both the statal passive, as in the (a) sentences below, and the processual passive, as in the (b) sentences below.

(49) a. His hands were pushed into his pockets while his teacher was talking to him.

b. His hands were pushed into his pockets every time his eyes met his teacher's.

(50) a. John's arms were thrown around Mary's neck while she was crying.

b. John's arms were thrown around every visitor upon their arrival.

Thus the different passive possibilities with these verbs should be described in terms of their possibilities with respect to each type of passive. Sections 4.2 and 4.3 examine the processual and statal types of passives, respectively.

\subsection{The Processual Type}

\subsubsection{An Issue}

It is widely accepted that an element encoded as subject has the highest degree of focus. Thus when the speaker wants to focus on the transitive object rather than on the subject, the passive is preferred to the unmarked active (e.g. Dixon (1991: Ch. 9) and Shibatani (1985)). The contrast in passivisability between the bodily motion use of slap and wipe, as in (43b) and (44b), and that of push and throw, as in (45b) and (46b), indicates that in construing events encoded by the bodily motion use of slap and wipe, it is impossible to give more prominence to the body part moved than its owner; but in construing events encoded by the bodily motion use of push and throw, the body part may gain an appropriate degree of importance. Why is this so? Adopting the concept of "force dynamics" developed by Talmy (2003a: Ch. 7), this paper demonstrates that this difference comes from the difference in the degree of conflict between the body part and its owner. 
4.2.2. Talmy's (2003a) Force Dynamics

By "force dynamics" Talmy (2003a: Ch. 7) means the way one entity interacts with another with respect to force. The contrast between expressions exhibiting force-dynamic patterns and expressions describing force-dynamically neutral events is exemplified by the following pair.

(51) a. The ball was rolling along the green.

b. The ball kept (on) rolling along the green.

(Talmy (2003a: 412))

(51a) does not involve a force opposition but (51b) involves either of the following two force-dynamic patterns: one is that the ball's tendency toward rest is being overcome by external force like the wind; the other is that the ball's tendency toward motion is overcoming external opposition like stiff grass.

The pair of sentences in (51) refer to events in the purely physical domain. According to Talmy, the force-dynamic concept is found in a succession of semantic domains, as exemplified below.

a. He didn't close the door.

b. He refrained from closing the door. (Talmy (2003a: 412))

In (52), while both sentences refer to a person's nonaction, the (b) sentence adds to this the sense of a conflict within a single psyche. Here the force-dynamic concept is applied to the intrapsychological domain and this sentence encodes a conflict between a person's urge to act and the same person's stronger inhibition against acting. ${ }^{10}$ Talmy (2003a: 463-464) mentions the force-dynamic interpretation of the pushing and pulling acts with the purpose of distinguishing one from the other in his discussion about important distinctions found in the force-dynamic system. Since the distinction between the two forms of force exertion is not of interest here, let us just report that his analysis treats these

10 As mentioned in note 2, the study by Talmy (2003a) and the studies by Lakoff (1996) and Lakoff and Johnson (1999) deal with a similar range of expressions including (52b) and sentence (ib) in note 2, i.e., I restrained myself from hitting him. Although they also advance a similar view, their interests seem to differ. Talmy's study is mainly concerned with the role that the force-dynamic concept plays in linguistic analyses. Thus in his analysis, the expressions in question are cited to prove the significance of force dynamics. Lakoff and Johnson's studies, on the other hand, are mainly concerned with the metaphor system for conceptualizing the self. Thus in their analysis, the expressions in question are cited to demonstrate how a person is understood in terms of entities in the physical domain. This is why I introduced their studies at different places in this paper. 
events as involving a force opposition between an entity that has a tendency toward rest and some external force acting on it.

Talmy (2003a: 449) also points out that not only forces of the same domain but also those of two different domains may clash, as illustrated below.
a. John finally agreed.
b. The lizard finally moved.

(Talmy (2003a: 449))

In (53a), an opposition is found between two forces in the same interpersonal domain; but in (53b), an opposition is found between actuality and the speaker's desire, thus yielding a cross-domain clash. That is, while the lizard's motion is not brought about under pressure from the speaker to move, the occurrence of the motion is expressed as a form of force opposition.

\subsubsection{Analysis}

In Talmy's force dynamic system, the stronger/weaker distinction is employed to specify the relative strengths of two opposing forces. In his system, the entity that is able to manifest its tendency at the expense of its opposer is considered to be the stronger. Apart from this, the present analysis takes into consideration the strength of opposition, i.e. the degree of conflict between two opposing forces.

Having established some relevant notions, we now turn to the question of why a body part can gain more prominence than its owner in the event expressed by the bodily motion use of push or throw, but not in the event expressed by the bodily motion use of slap or wipe, yielding the contrast as to passivisation.

We will first consider the case of push and throw. As we have stated in section 3.2, body-control push and throw involved in the bodily motion use of these verbs encode some act needing force or a sudden movement. Native speakers seem to have the intuition that both objectcontrol throw and body-control throw describe a forceful or sudden movement, as suggested by the following quote from the Collins COBUILD Advanced Learner's English Dictionary (2006) (=CCALED).

(54) When you throw an object that you are holding, you move your hand or arm quickly and let go of the object, so that it moves through the air.

(55) If you throw your body or part of your body into a particular position or place, you move it there suddenly and with a lot of force. 
With push, CCALED makes no reference to the body-control sense. However, with its semantic companion, pull, the dictionary refers to the body-control sense, seeing the object-control and body-control senses as equally distinct. ${ }^{11}$ Thus, let us illustrate the point with the relevant definitions of pull given in CCALED.

(56) When you pull something, you hold it firmly and use force in order to move it towards you or away from its previous position.

(57) If you pull yourself or pull a part of your body in a particular direction, you move your body or part of your body with effort or force.

These observations indicate that the notions of force and suddenness figure in the semantics of verbs relating to exerting force like pull, push, and throw. ${ }^{12}$ Now let us consider the notions of force and suddenness in turn. As for force, given that body-control push and throw are metaphorical extensions from object-control push and throw, knowledge about a force opposition between an entity that has a tendency toward rest and some external force acting on it is considered to be mapped. Thus the opposition relation holds not only between the pusher/thrower and external-pushed/thrown roles of object-control push and throw but also between the pusher/thrower and internal-pushed/ thrown roles of body-control push and throw. This paper suggests that this force opposition accords a body part the right sort of salience for it to be passive subject.

As for the notion of suddenness, it can also be related to a force opposition. Remember Talmy's (2003a) observation that in (53b), forces of two different domains, i.e. actuality and the speaker's expectation, clash. The same is true of the suddenness of bodily motion. The

11 The disparity in the treatment of the body-control sense between push and pull is also found in some other dictionaries. For example, Macmillan English Dictionary for Advanced Learners of American English. (2002) makes reference to the body-control sense for pull but not for push. Oxford Advanced Learner's Dictionary of Current English (2000) recognizes this sense for both pull and push but it does not see the two senses as distinct in the case of push. While this disparity raises an interesting question as to its cause, I will not pursue this point further.

${ }^{12}$ It should be noted here that the bodily motion use of pull is open to passivisation, as illustrated below.

(i) a. He pulled his head back.

b. His head was pulled back. 
sense of suddenness is associated with the movement that happens against the speaker's expectation. This disparity between actuality and the speaker's expectation yields a cross-domain clash, which gives the body part moved the right degree of salience.

Let us next consider the case of slap and wipe. As we have discussed in section 3.1, the bodily motion use of these verbs can depict the same slapping or wiping act as that depicted by the transitive use. Then what we need to ask is whether there is a considerable degree of conflict between the slapper or wiper and the intermediate in a usual slapping or wiping event. As far as the slapper/wiper causes the intermediate, which has a tendency toward rest, to move, the bodily motion involved can be regarded as involving a kind of causation. ${ }^{13}$ However, it is unlikely that the slapper/wiper and intermediate roles oppose each other, as the pusher/thrower and internal-pushed/thrown do, because the intermediate (i.e. the body part) is supposed to follow the slapper/ wiper's (i.e. its owner's) will. When the body part resists its owner's will in such a way as to make it difficult for the person to slap or wipe, such a bodily motion event is unlikely to be expressed with verbs like slap or wipe.

To summarize, in bodily motion events, a body part can gain an appropriate degree of significance for it to be a passive subject, when a given event is interpreted as involving a fairly strong opposition of force between the body part and its owner. One thing worth mentioning at this point is that the relevance of the notion of a fairly strong force opposition to the determination of the passive possibility can be seen elsewhere. In studies of periphrastic causatives, it has been observed that unlike make or force, have is not found in the passive

13 Talmy (2003a: Ch. 8) seems to share this view when he explains the entailment of a sentence like (i).

(i) I killed the snail by hitting it with my hand.

Talmy points out that sentence (i) cannot entail the possibility expressed by (ii) or (iii).

(ii) The snail died as a result of the wind blowing my hand against it.

(iii) The snail died as a result of my hand hitting it by a spasm.

Construing the body part event as caused by an act of volition on the part of its owner, Talmy states as follows: "While it is not clear what final semantic status this volitional act should be accorded, it can be provisionally regarded as a particular nonphysical variety of causing event (p. 512)." 
(e.g. Dixon (1991: 195) and Hollmann (2006)). ${ }^{14}$ According to Hollmann, have, as opposed to force, entails that the causer is inherently in control of the causee, thus ensuring the success of the interpersonal manipulation. This situation contrasts with the causative situation expressed by force, which has higher degree of transitivity in that the interpersonal manipulation is done using force. He attributes the unacceptability of a passive sentence with periphrastic causative have to this factor.

\subsection{The Statal Type}

The passive may also be used to focus on the result of an activity (e.g. Dixon (1991: Ch. 9)). Thus events which are suitable for description through the statal passive need to involve a particular result. The verbs push and throw meet this requirement. Pushing or throwing a body part in a direction may have a result because a body part pushed or thrown ends up placed at a particular location. This is analogous with the case of throwing a physical entity and some cases of pushing a movable physical entity, where the physical object ends up in a certain position in space. This is why push and throw are compatible with the statal passive.

By contrast, the verbs slap and wipe do not meet this requirement. In a slapping or wiping act, while the body part used undergoes a location change in that it makes contact with the target, it is unlikely that the body part stays there after the act. The body part is likely to return to its usual position somewhere near the central body axis. In this respect, the verbs slap and wipe differ from the verbs push and throw and block passivisation.

It is interesting to note here that the passive can be used to depict a state that does not have to be the result of the event denoted by the verb involved, as discussed in Matsumoto (1996) and Talmy (2003a: 134-136). In a survey of BNC, I find such expressions with push and pull, as exemplified below.

(58) a. His face was young, but his shoulders were bent like an old man's and his head was pushed forward. (BNC)

14 Hollmann (2006: 193) illustrates this point with the following data.

(i) a. Recruits [...] were made to hop on the spot.

b. *Recruits were had to hop on the spot. 
b. The long thin mouth was pulled down at the corners like a tragic mask, the eyes were hooded, the shoulders hunched, head bent forward so that the man's gaze seemed fixed on the surface of the table. (BNC)

The sentences in (58) describe what a person looks like. Here spatial configurations characteristic of the persons talked about are described in terms of the fictive motion of particular body parts to their sites. Since in these examples the occurrence of a real pushing or pulling event is not presupposed, they are better seen as subjective-change expressions. The existence of such expressions suggests that verbs of exerting force like pull and push imply a motion event which ends up in a particular position in space or a particular spatial configuration.

\section{The Path Phrase}

In this final section, we turn our attention to a path phrase in bodily motion expressions. An observation of naturally occurring instances in the BNC indicates that verbs relating to contact like slap and wipe and those relating to exerting force like push and throw are found with a variety of path expressions. Slap and wipe occur with phrases headed by prepositions like across, against, on, and over. Push and throw occur with a wider range of directional phrases, including prepositional phrases marked by about, above, across, against, around, beneath, between, down, in, inside, into, out of, over, through, round, or under. Push and throw also occur with particles like back, down, forward, or up.

As we have seen in the introduction, the verbs slap, wipe, push, and throw can be used to encode an event in which a person expressed as subject moves his/her body part expressed as object in a direction only when they are followed by a path phrase. To consider how a constructional approach deals with such a case, let us briefly review Goldberg's constructional analysis of a similar phenomenon. Goldberg (1995) observes that the caused motion sense of sneeze or laugh, shown in (59) and (60), only occurs in the caused motion construction (i.e. what we call the externally caused motion construction).

(59) Frank sneezed the napkin off the table.

(Goldberg (1995: 154))

(60) The audience laughed the poor guy off of the stage. (ibid.) On a constructional approach, argument structure is paired with mean- 
ing. Since a construction carries meaning independently of a verb in a sentence, the meaning of the whole sentence is partly attributable to the construction. In examples like (59) and (60), the caused motion sense is contributed not by the verbs involved but by the construction.

In the literature on verbs and argument structure, it has been observed that many verbs exhibit a range of variation in meaning and syntactic context and a particular meaning occurs when the verb appears in a particular syntactic frame. While a lexical semantic analysis like Levin and Rappaport Hovav $(1991,1995)$ differs from a constructional analysis in that it attributes the variation in meaning not to the construction but to the verb involved, these approaches seem to provide similar insights into the variation in meaning associated with a verb, as noted in Rappaport Hovav and Levin (1998) and Jackendoff (1997). For example, Levin and Rappaport Hovav (1995: Ch. 2) explain that when the verb wash manifests an extended sense as verbs of removal it is expected to express its argument like other verbs of removal, as shown below.

(61) a. The weaver rinsed the dye out of the material.

b. *The weaver rinsed (the dye).

(Levin and Rappaport Hovav (1995: 65)) Their view that when a given verb acquires an extended sense it is found in the syntactic frame typical of the extended meaning can be taken to be translatable into the constructional approach.

It should also noted here that what Fillmore and Atkins (1992) call "derivative syntax" in their frame semantic analysis looks not unlike the lexical rules in the above mentioned lexical semantic studies. By "derivative syntax," Fillmore and Atkins (1992) mean a process through which a given word incorporates some of the syntax associated with certain other words and acquires their meanings as its secondary senses. They point out that there are many examples where extended uses of a verb exhibit distributional and semantic properties of associated verbs. To illustrate this point, let us cite their example of a secondary sense of risk.

(62) He's likely to risk a week's salary on a horse.

(Fillmore and Atkins (1992: 98))

They claim that this sentence inherits some of the syntax and semantics of the verb bet and thus the on-phrase and the gambling sense is involved.

While this paper adopts the framework of Construction Grammar, the 
insights of these studies will help us explain why the bodily motion use of the verbs slap, wipe, push, and throw cannot omit the path phrase, as shown in (4)-(7).

(4) a. He slapped his hand on the table.

b. \#He slapped his hand. $(\neq(4 a))$

(5) a. John wiped his hand across his mouth.

b. \#John wiped his hand. $(\neq(5 \mathrm{a}))$

(6) a. John pushed his hands into his pockets.

b. \#John pushed his hands. $(\neq(6 a))$

(7) a. John threw his arms around her neck.

b. \#John threw his arms. $(\neq(7 \mathrm{a}))$

Let us first consider the case of wipe. If the path phrase is omitted from a sentence like (5a), the resulting sentence becomes an instance of the transitive construction. The transitive construction is used to encode the relation between agent and patient. The agent and patient roles fuse with the wiper and wiped roles, as represented in (25). Our question is why the agent and patient roles do not fuse with the wiper and intermediate roles, as represented below.

(63) participant roles: <wiper, intermediate>

argument roles: [agent, patient]

This is because the notion of contact constitutes the core of the meaning of wipe and the notion can be found in the relation between the wiper and the wiped but not in the relation between the wiper and the intermediate. This makes the wiper the ideal candidate for the patient in the wiping event. The same line of argument applies to the case of slap. $^{15}$

Let us next consider the case of push. As we have seen in section 3.2, object-control push encodes an event in which a pusher exerts force on an external-pushed to move it, where any subsequent motion of the external-pushed is not necessarily involved. This source domain information is mapped onto the target domain and thus body-control push does not entail the motion of the internal-pushed either. Then in order that the verb may encode the motion sense, it must occur in a construction with the motion sense, i.e. the internally or externally caused

15 In his comprehensive description of slap, Ruhl (1989: Ch. 8) also claims that the notion of contact figures in the semantics of this verb, addressing the fact in (4). 
motion construction, rather than the transitive construction, which does not carry the motion sense by itself.

As we have addressed in section 3.2, at a more fine-grained level of description, body-control throw differs from body-control push in that the former entails motion of the entity the actor holds, since in a throwing event the actor lets go of the entity s/he holds. However, this source domain information is not mapped onto the target domain. With regards to limitations on metaphorical mappings, Lakoff (1993: 216) advances what he calls "the Invariance Principle" and explains that part of source domain knowledge may not be mapped onto the target domain when it is not consistent with the inherent structure of the target domain. Following this, we can explain that knowledge about throwing a distinct physical entity like a ball cannot be mapped onto the target domain because in a bodily motion event a person never lets go of his/her body part. Thus as with body-control push, body-control throw needs to be integrated into a construction with the motion sense in order to depict an event in which the body part in object slot is moved in some direction.

So far we have shown that bodily motion expressions with verbs relating contact like slap and wipe and those relating to exerting force like push and throw cannot omit the path phrase because these verbs do not inherently encode the motion sense and thus need to inherit the sense from the construction. These verbs contrast with a verb which inherently encodes the motion sense. For example, the verb lift specifies an inherent direction of motion. This verb can be used to encode motion of the body part in object slot without a path phrase, as shown below.

(8) a. I lifted my arm.

(64) Cassie lifted her arms to reach his neck. (BNC)

The reason why lift can encode motion of the body part expressed as object without a path phrase is because the motion sense is inherent in the meaning of the verb and thus it need not be contributed by a construction which is associated with the motion sense.

Before we conclude our discussion, let us consider the fact that verbs like wiggle can encode bodily motion without a path phrase, as shown by Lakoff and Johnson's (1999) example in (8b).

(8) b. I can wiggle my ears.

This type of bodily motion is distinguished from the type encoded by the verbs discussed so far. In the case of verbs like slap, wipe, push, 
throw, and lift, the path component is included in the semantics of the expression, whether implicit or explicit, but in the case of verbs like wiggle, the bodily motion expression does not include a path, even as an implicit argument. If we adopt the distinction between a GO-function and a MOVE-function, discussed in Jackendoff (1990), the wiggle expression in (8b) is taken to be an instance of MOVE rather than GO.

\section{Conclusion}

This paper has been concerned with bodily motion expressions with verbs relating to contact like slap and wipe, as in John wiped his hand across his mouth, and those with verbs relating to exerting force like push and throw, as in John threw his arms around her neck. This study has pointed out that these apparently similar expressions manifest divergent properties as to the kinds of body-part objects permitted and passivisation, points not discussed in the literature, as far as I know. Adopting Lakoff and Johnson's internal causation metaphor, this study has characterized these bodily motion expressions as instances of what we call the internally caused motion construction. If we just characterize these apparently similar expressions uniformly as encoding a person's moving his/her body part in a way characteristic of the event described by the verb, we cannot explain the divergences between them. By examining the interaction between verbs and constructions within the framework of Construction Grammar, this study has shown that the two groups of verbs obtain the bodily motion use through different processes and that this difference produces the difference as to selection restrictions.

Concerning passivisation, the present analysis suggests that conditions under which a body-part object can be passive subject include the following: as for the processual type, when there is a considerable force opposition between a body part and its owner, the body part can gain the right sort of significance for it to be passive subject; and as for the statal type, when a body part is placed at a particular location as a result of a bodily motion event, the body part can be a passive subject. This suggestion is significant because passive sentences with body-part subject have not been discussed in depth, though the presence of such examples is reported by studies like Levin (1993) and Stein (1979).

This paper sheds light on bodily motion expressions involving a theme and a path argument, i.e. instances of GO as opposed to MOVE. 
To borrow Talmy's (2003b: 35-37) terms, the bodily motion events this paper is concerned with involve "translational motion" rather than "selfcontained motion." In the literature on motion events, examples of bodily motion events almost always refer to instances of MOVE like Willy wiggled, which takes a single argument, and such examples are contrasted with motion events in which the subject or the object undergoes a change of location, as in The rock rolled down the hill or I rolled the keg into the storeroom. As one notable exception, Iwata (2004) analyzes an expression like He jumped to his feet as involving the type of motion that is distinct from both self-contained motion and translational motion. (See Iwata (2004) for details.) I believe that the present analysis contributes to the elucidation of an entire system for the expression of motion events.

\section{REFERENCES}

Curme, George O. (1931) A Grammar of the English Language, D.C. Heath and Company, Boston.

Dixon, R. M. W. (1991) A New Approach to English Grammar, on Semantic Principles, Clarendon Press, Oxford.

Dowty, David (1991) "Thematic Proto-Roles and Argument Selection," Language 67, 547-619.

Fillmore, Charles J. (1977) "The Case for Case Reopened," Grammatical Relations, Syntax and Semantics 8, ed. by Peter Cole and Jerrold. M. Sadock, 59-81, Academic Press, New York.

Fillmore, Charles J. (1982) "Frame Semantics," Linguistics in the Morning Calm, ed. by the Linguistic Society of Korea, 111-137, Hanshin, Seoul.

Fillmore, Charles J. and Beryl T. Atkins (1992) "Toward a Frame-Based Lexicon: The Semantics of RISK and Its Neighbors," Frames, Fields, and Contrasts: New Essays in Lexical Organization, ed. by Adrienne Lehrer and Eva F. Kittay, 75-102, Lawrence Erlbaum Associates, Hillsdale, NJ.

Fillmore, Charles J. and Beryl T. Atkins (1994) "Starting where the Dictionaries Stop: The Challenge of Corpus Lexicography," Computational Approaches to the Lexicon, ed. by Beryl T. Atkins and Antonio Zampolli, 349-393, Oxford University Press, Oxford.

Fillmore, Charles J. and Paul Kay (1993) "Construction Grammar Coursebook," ms., University of California, Berkeley.

Goldberg, Adele E. (1995) Constructions: A Construction Grammar Approach to Argument Structure, University of Chicago Press, Chicago.

Goldberg, Adele E. and Ray Jackendoff (2004) "The English Resultative as a Family of Constructions," Language 80, 532-568. 
Grunau, Justin J. M. (1985) "Towards a Systematic Theory of the Semantic Role Inventory," CLS 21, 144-159.

Hollmann, Willem (2006) "Passivisability of English Periphrastic Causatives," Corpora in Cognitive Linguistics: Corpus-Based Approaches to Syntax and Lexis, ed. by Stefan Th. Gries and Anatol Stefanowitsch, 193-223, Mouton de Gruyter, Berlin/New York.

Iwata, Seizi (2004) "He Jumped to His Feet: Internal Motion and Internal Path," Tsukuba English Studies 22, 89-99.

Jackendoff, Ray (1990) Semantic Structures, MIT Press, Cambridge, MA.

Jackendoff, Ray (1997) "Twistin' the Night Away," Language 73, 534-559.

Jespersen, Otto (1927) A Modern English Grammar on Historical Principles, Part 3 Syntax, vol. 2, Carl Winter, Heidelberg.

Kageyama, Taro and Yoko Yumoto (1997) Gokeisei to Gainen-Kozo (Word Formation and Conceptual Structure), Kenkyusha, Tokyo.

Kay, Paul and Charles J. Fillmore (1999) "Grammatical Constructions and Linguistic Generalizations: The What's X Doing Y Construction," Language $75,1-33$.

Lakoff, George (1993) "The Contemporary Theory of Metaphor," Metaphor and Thought, 2nd ed., ed. by Andrew Ortony, 202-251, Cambridge University Press, Cambridge.

Lakoff, George (1996) "Sorry, I'm Not Myself Today: The Metaphor System for Conceptualizing the Self," Space, Worlds, and Grammar, ed. by Gilles Fauconnier and Eve Sweetser, 91-123, University of Chicago Press, Chicago.

Lakoff, George and Mark Johnson (1999) Philosophy in the Flesh: The Embodied Mind and Its Challenge to Western Thought, Basic Books, New York.

Langacker, Ronald W. (1982) "Space Grammar, Analysability, and the English Passive," Language 58, 22-80.

Levin, Beth (1993) English Verb Classes and Alternations: A Preliminary Investigation, University of Chicago Press, Chicago.

Levin, Beth and Malka Rappaport Hovav (1991) "Wiping the Slate Clean: A Lexical Semantic Exploration," Cognition 41, 123-151.

Levin, Beth and Malka Rappaport Hovav (1995) Unaccusativity: At the SyntaxLexical Semantics Interface, MIT Press, Cambridge, MA.

Matsumoto, Yo (1996) "Subjective-Change Expressions in Japanese and Their Cognitive and Linguistic Bases," Space, Worlds, and Grammar, ed. by Gilles Fauconnier and Eve Sweetser, 124-156, University of Chicago Press, Chicago.

Nakau, Minoru (1997a) "Dogu Atsukaika Basho Atsukaika-Nichieigo ni Miru Chikaku no Kuse to Kobunkei- (Instrument or Location?: Patterns in Perception and Construction in English and Japanese)," Baiko Jogakuin Daigaku Kokai Koza Ronsyu 40, 5-23.

Nakau, Minoru (1997b) “The 'Actional' Passive Is No More," Studies in 
English Linguistics: A Festschrift for Akira Ota on the Occasion of His Eightieth Birthday, ed. by Masatomo Ukaji et al. 739-751, Taishukan, Tokyo.

Norvig, Peter and George Lakoff (1987) "Taking: A Study in Lexical Network Theory," BLS 13, 195-206.

Rappaport Hovav, Malka and Beth Levin (1998) "Building Verb Meanings,"

The Projection of Arguments: Lexical and Compositional Factors, ed. by

Miriam Butt and Wilhelm Geuder, 97-134, CSLI Publications, Stanford.

Ruhl, Charles (1989) On Monosemy: A Study in Linguistic Semantics, State University of New York Press, Albany.

Shibatani, Masayoshi (1985) "Passives and Related Constructions: A Prototype Analysis," Language 61, 821-848.

Stein, Gabriele (1979) Studies in the Function of the Passive, Gunter Narr Verlag, Tübingen.

Talmy, Leonard (2003a) Toward a Cognitive Semantics, vol. 1, Concept Structuring Systems, MIT Press, Cambridge, MA.

Talmy, Leonard (2003b) Toward a Cognitive Semantics, vol. 2, Typology and Process in Concept Structuring, MIT Press, Cambridge, MA.

\section{Corpus}

British National Corpus (provided by Shogakukan Corpus Network (http://scn02. corpora.jp/ sakura04/cgi-bin/login1.cgi)) [BNC]

\section{Dictionaries}

Collins COBUILD Advanced Learner's English Dictionary, 5th ed. (2006)

Macmillan English Dictionary for Advanced Learners of American English (2002)

Oxford Advanced Learner's Dictionary of Current English, 6th ed. (2000)

Faculty of Human Development and Culture

Fukushima University

1 Kanayagawa, Fukushima-shi

Fukushima 960-1296

e-mail: nemoto@educ.fukushima-u.ac.jp 